\title{
Technologies, Design, and Applications of Low-Noise Amplifiers at Millimetre-Wave: State-of-the-Art and Perspectives
}

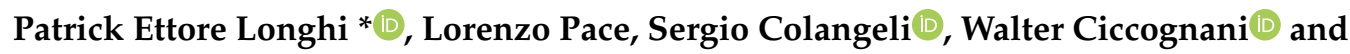 \\ Ernesto Limiti ${ }^{D}$ \\ Electronic Engineering Department, Università di Roma Tor Vergata, 00131 Roma, Italy; \\ lorenzo.pace@uniroma2.it (L.P); sergio.colangeli@uniroma2.it (S.C.); walter.ciccognani@uniroma2.it (W.C.); \\ limiti@ing.uniroma2.it (E.L) \\ * Correspondence: longhi@ing.uniroma2.it; Tel.: +39-06-7259-7343
}

Received: 27 September 2019; Accepted: 24 October 2019; Published: 25 October 2019

\begin{abstract}
An overview of applicable technologies and design solutions for monolithic microwave integrated circuit (MMIC) low-noise amplifiers (LNAs) operating at millimeter-wave are provided in this paper. The review starts with a brief description of the targeted applications and corresponding systems. Advanced technologies are presented highlighting potentials and drawbacks related to the considered possibilities. Design techniques, applicable to different requirements, are presented and analyzed. An LNA operating at V-band (59-66 GHz) is designed and tested following the presented guidelines, demonstrating state-of-the-art results in terms of noise figure (average $\mathrm{NF}<2 \mathrm{~dB}$ ). A state-of-the-art table, reporting recent results available in open literature on this topic, is provided and examined, focusing on room temperature operation and performance in cryogenic environment. Finally, trends versus frequency and perspectives are outlined.
\end{abstract}

Keywords: low-noise amplifiers; MMICs; millimeter-wave; high electron mobility transistor; gallium arsenide; indium phosphide

\section{Introduction}

Millimeter-wave is the frequency portion of the radiofrequency spectrum included between 30 and $300 \mathrm{GHz}$, i.e., those frequency values for which the wavelength (in air) is between $1 \mathrm{~cm}$ and a $1 \mathrm{~mm}$. Millimeter-wave low-noise amplifiers (mmw-LNA) are the key-component in many receiving systems for high-end applications, especially those where system sensitivity is the main parameter.

Systems requiring high-performance receivers are scientific instruments for observation of the universe [1] or space-borne earth-sensing. Such instruments are based on interferometric techniques synthesized by large arrays or very large parabolic dishes. The receiver relies on specific niche technologies often cryogenically cooled to enhance system sensitivity.

As semiconductor technologies improve their performance, and most of all become more reliable, satellite telecom systems or ground-based safety and security applications (concealed weapon detectors, vehicular guidance, and so on) are becoming more practical [2]. Finally, wireless communication systems are also moving to millimeter-wave since technologies featuring gate lengths shorter than $100 \mathrm{~nm}$ are becoming relatively inexpensive and more easily accessible worldwide.

As a consequence, there is also need for mmw-LNA realized with industrial-grade technology.

\section{State-of-the-Art Technologies for mmw-LNA}

Low-noise amplification at millimeter-wave requires semiconductor technologies with a current gain cut-off frequency $\left(f_{T}\right)$ well above the few hundreds of GHz limit, in order to provide acceptable 
performance at least up to $300 \mathrm{GHz}$. Few technologies are capable of fulfilling such requirement and even less are industrial-grade ones. Most are available in research labs, and some, typically the ones originating in the USA, may be subject to export restriction or end user certification.

Current state-of-the-art mmw-LNA are realized either in indium phosphide (InP) high electron mobility transistor (HEMT) or gallium arsenide (GaAs) metamorphic HEMT (mHEMT) with gate lengths shorter than $100 \mathrm{~nm}$. The latter parameter represents, nowadays, a "threshold" value for millimeter-wave operation. In fact, the great majority of mmw-LNAs analyzed in this review are realized featuring a gate length equal or shorter than $100 \mathrm{~nm}$.

HEMT is in hetero-structure transistor where a two-dimensional electron gas (2DEG) is created at the interface of two different contacting material due to their different energy bandgaps. Such 2DEG present very high electron saturation velocity and is well suited for high-frequency and low-noise applications.

In the following, the main features of each technology and how each one can be gainfully employed to achieve low-noise performance are briefly described. Akgiray et al. provide a recent and detailed analysis of technologies for ultra-low-noise applications for operation at millimeter-wave and the relative transistor noise model in [3].

\subsection{Indium Phosphide}

InP HEMT transistors have long been the semiconductor of choice for extremely low-noise amplifiers operating in RF, microwave, and millimeter-wave bands due to their superior noise and gain performance up to $300 \mathrm{GHz}$ and even above. Significantly developed in the 1990s, InP HEMT monolithic microwave integrated circuits (MMICs) can be found in both defense applications (such as secure communications) and scientific applications, which typically consist of some form of very high-frequency radiometry, capable of detecting the vanishing small signals travelling from outer space. On the other hand, among all semiconductors, InP experiences slow development due to its niche market and, consequently, tends to be one of the most expensive. Moreover, InP HEMT are unpractical to manufacture, especially in high volumes and, therefore, are relegated to be employed in non-critical applications. Finally, InP technology is extremely well suited for cryogenically cooled operation.

In the case of InP HEMTs, the hetero-structure, schematically depicted in Figure 1, is formed by $\mathrm{In}_{x} \mathrm{Ga}_{1-x} \mathrm{As} / \mathrm{In}_{y} \mathrm{Al}_{1-y} \mathrm{As}$.

\begin{tabular}{lr}
\hline InGaAs/InAlAs & $\mathrm{n}+$ composite cap layer \\
\hline InAlAs (schottky barrier) & o-doping \\
\hline InAlAs spacer & $\begin{array}{r}\text { composite } \\
\text { channel }\end{array}$ \\
\hline InGaAs & buffer \\
\hline InAs & substrate \\
\hline InGaAs
\end{tabular}

Figure 1. Epitaxial structure of an advanced indium phosphide ( $\mathrm{InP}$ ) high electron mobility transistor (HEMT).

Lattice-matched HEMTs are obtained when $x=0.53$ and $y=0.52$ while strained structures for $x>0.7$. Lattice-matched structures are more easily manufactured but noise performance improves as 
$x \rightarrow 1$. In fact, increasing the channel Indium concentration beyond the $53 \%$ lattice-matched condition results in the channel being under compressive strain as the lattice constant of the channel is less than that of the substrate and barrier layers. Providing the channel thickness is kept below some critical value, which depends on the indium concentration, the strain can be accommodated fully in the channel, which takes on the lattice constant of the InP substrate, resulting in a non-lattice-matched device. Increasing the indium concentration results in two effects from modification of the band structure of the channel layer:

1. The energy separation of the $\Gamma$ and $L$ valleys increases, meaning that carriers can accelerate for longer in the high mobility $\Gamma$ valley, and so attain a higher velocity before being scattered into the low mobility L valley.

2. The electron effective mass reduces, resulting in yet higher carrier mobility in the $\Gamma$ valley.

Both these effects increase the average velocity of carriers in the device channel and result in an increase in device trans-conductance and $f_{T}$ for a given gate length. The negative side of increasing the indium concentration is that the bandgap of the channel is reduced. This leads to greater impact ionization that reduces the device breakdown voltage, thus limiting the usefulness of such devices in realistic circuit applications. Consequently, InP breakdown voltage is rather low and typically does not exceed 2.5 V [3], making this process unpractical in medium-power applications. Examples are of available InP technologies are described in the following paragraphs.

\subsubsection{Chalmers University of Technology}

The epitaxial structure of this process, schematically depicted in Figure 1 and reported in greater detail in [4], consists of a typical lattice-matched structure $(x=0.53$ and $y=0.52)$. From top to bottom: A $20 \mathrm{~nm} \mathrm{In} 0.53 \mathrm{Ga}_{0.47}$ As cap layer doped to a Si concentration of $5 \times 10^{19} \mathrm{~cm}^{-3}$, an $11 \mathrm{~nm} \operatorname{In}_{0.52} \mathrm{Al}_{0.48} \mathrm{As}$ barrier, a $\left(5 \times 10^{12}\right) \mathrm{cm}^{-2}$ Si-delta doping, a $3 \mathrm{~nm} \mathrm{In}_{0.52} \mathrm{Al}_{0.48}$ As spacer, a $15 \mathrm{~nm} \operatorname{In}_{0.65} \mathrm{Ga}_{0.35}$ As channel, and a $250 \mathrm{~nm} \operatorname{In}_{0.52} \mathrm{Al}_{0.48}$ As buffer.

Hall measurements at room temperature of the structure with the cap layer etched away demonstrated electron mobility and sheet carrier concentration of $11,400 \mathrm{~cm}^{2} / \mathrm{V} \cdot \mathrm{s}$ and $2.8 \times 10^{12} \mathrm{~cm}^{-2}$, respectively. The source-drain distance is $1.2 \mu \mathrm{m}$, while the gate length is $130 \mathrm{~nm}$.

\subsubsection{NGC, Northrop Grumman Corporation}

Northrop Grumman Corporation's (NGC) $35 \mathrm{~nm}$ InP HEMT process [5] has produced state-of-the-art results well above $100 \mathrm{GHz}$, as reported in Section 4. Two variants of the process are available with different indium mole fractions in the active $\operatorname{In}_{x} \mathrm{Ga}_{1-x}$ As layer, $x=0.75$ and $x=1.0$, respectively. Both processes are grown on a $50-\mu \mathrm{m}$-thick substrate in order to guarantee adequate performance at extremely high frequencies. The version with $100 \%$ Indium content has approximately $35 \%$ higher trans-conductance $\left(g_{m}\right)$ than the version with $75 \%$ Indium: 2300 vs. $1700 \mathrm{mS} / \mathrm{mm}$.

\subsubsection{ETH Zürich}

ETH Zürich developed a very interesting $100 \mathrm{~nm}$ InP pHEMT process [6,7]. Starting from the 4 inch semi-insulating InP substrate, the layer stack consists of an InAlAs buffer, a pseudomorphic $\mathrm{In}_{0.68} \mathrm{Ga}_{0.32} \mathrm{As}$ channel, an $\operatorname{In}_{0.45} \mathrm{Al}_{0.55} \mathrm{As}$ Spacer, a Si delta-doped layer, an $\operatorname{In}_{0.45} \mathrm{Al}_{0.55} \mathrm{As}$ barrier, a $3 \mathrm{~nm}$ InP etch stop layer, and an $\mathrm{n}^{+}$InGaAs cap layer. Hall measurements conducted at room temperature show an electron mobility of $12,000 \mathrm{~cm}^{2} / \mathrm{V} \cdot \mathrm{s}$ and a sheet carrier density of $3.0 \times 10^{12} \mathrm{~cm}^{-2}$. This technology shows a $f_{T}$ and $f_{M A X}$ up to $270 \mathrm{GHz}$ and $350 \mathrm{GHz}$, respectively, and a maximum $g_{m}$ equal to $1100 \mathrm{mS} / \mathrm{mm}$, thus enabling advanced performance with very low power consumption. The average minimum noise figure associated with this technology in the DC-20 GHz frequency band is $0.3 \mathrm{~dB}$, with an associated gain equal to $18.3 \mathrm{~dB}$ at $10 \mathrm{GHz}$. 


\subsection{Gallium Arsenide}

The advantages of GaAs substrate over InP are lower manufacturing costs, improved power handling capability, and larger wafer size available for production [8]. Due to increasing number of receiving elements, there is an emphasis on cost, yield, and process stability. Consequently, GaAs is commercially more attractive and has enjoyed significant investment in process development over the last decade.

Good crystal quality is achieved with the use of a metamorphic transitional buffer layers between the GaAs substrate and the active device layers of the InGaAs/InAlAs family to adapt the Indium lattice constant in the active channel to the GaAs substrate. A typical epitaxial hetero-structure of GaAs mHEMT is shown in Figure 2.

\begin{tabular}{|c|c|}
\hline InGaAs & $\mathrm{n}+$ cap layer \\
\hline \multicolumn{2}{|c|}{ AlGaAs (schottky barrier) } \\
\hline \multicolumn{2}{|l|}{ AlGaAs spacer } \\
\hline \multicolumn{2}{|c|}{ InGaAs or InAs Channel } \\
\hline \multicolumn{2}{|l|}{ InAlAs spacer } \\
\hline \multicolumn{2}{|l|}{ InAlAs } \\
\hline InAlAs/AlGa & metamorphic transition \\
\hline GaAs & substrate \\
\hline
\end{tabular}

Figure 2. Epitaxial structure of an advanced gallium arsenide (GaAs) metamorphic HEMT (mHEMT).

\subsubsection{IAF, Fraunhofer Institute for Applied Solid State Physics}

The technology is based on a $50 \mathrm{~nm}$ or $35 \mathrm{~nm}$ gate-length InAlAs/InGaAs mHEMT [9]. A metamorphic buffer is used for a lattice-matched growth of the HEMT layers on $100 \mu \mathrm{m}$ semi-insulating GaAs wafers. The 2DEG is confined in a composite $\operatorname{In}_{0.8} \mathrm{Ga}_{0.2} \mathrm{As} / \mathrm{In}_{0.53} \mathrm{Ga}_{0.47} \mathrm{As}$ channel. After the front side process, a full back side process follows. This includes wafer thinning to $50 \mu \mathrm{m}$ thickness, through substrate via holes, and back side metallization. Apart from the standard process, a noise-optimized variation is available. The major difference is that the "noise-variant" utilizes only the $\operatorname{In}_{0.8} \mathrm{Ga}_{0.2}$ As main channel and no composite channel

\subsubsection{OMMIC}

Transistors are built in a mHEMT technology process, called D007IH, with $70 \mathrm{~nm}$ gate length. For such small gate lengths, the static fringing capacitance of the gate becomes the main limitation to performance for the given epitaxial structure. This has led the foundry to develop a double T-shape gate topology (also taking care of the vertical dimension) [1]. The active component is based on an InGaAs/InAlAs hetero-structure and a conductive channel with $52 \%$ and $70 \%$ indium content, respectively, to obtain low-noise performance at operating frequencies above $100 \mathrm{GHz}$. In this process, a special type of graded buffer (metamorphic) is used to ensure an adequate transition between the GaAs substrate and the active layer, which are not lattice matched due to the high indium content. The process provides a current gain cut-off frequency $\left(f_{T}\right)$ of $300 \mathrm{GHz}$ and a maximum oscillation frequency $\left(f_{M A X}\right)$ of $350 \mathrm{GHz}[10]$. The drawback for the above-mentioned advanced figures of merits 
is a rather low breakdown voltage $(-3 \mathrm{~V})$, due to the high indium content in the channel. The wafer is typically thinned down to $100 \mu \mathrm{m}$ or even down to $70 \mu \mathrm{m}$ when higher frequency operation is required.

\subsubsection{BAE Systems Microelectronics Centre}

The epitaxial structures for mHEMT fabrication are grown by molecular beam epitaxy on semi-insulating GaAs substrates. The structures consist of a graded InAlAs metamorphic buffer, a high-indium InGaAs channel, an InAlAs gate layer, and a highly doped InGaAs cap layer. Two channel designs are available: Structure A has an $80 \%$ InGaAs channel with a silicon planar doping only above the channel, and structure B has a composite channel containing an InAs layer, with silicon planar doping both above and below the channel. For structures $\mathrm{A}$ and $\mathrm{B}$, the typical room-temperature sheet carrier densities were around $3.3 \times 10^{12}$ and $3.8 \times 10^{12} \mathrm{~cm}^{-2}$, respectively. Correspondingly, the room-temperature electron mobility was around 11,500 and $12,000 \mathrm{~cm}^{2} / \mathrm{V} \cdot \mathrm{s}$. It is worth noting that structure B has both higher sheet carrier density and electron mobility than structure A. On both structures $A$ and $B$, the gate length is $50 \mathrm{~nm}$ [11].

\subsection{HEMT Technology Performance Summary}

Table 1 presents a summary of the key features of the listed technologies. All are suitable for very high-frequency applications in conjunction with low power consumption, thanks to high $g_{m}$.

Table 1. Presented HEMT technologies performance summary.

\begin{tabular}{cccccccccc}
\hline Foundry & Substrate & $\begin{array}{c}\mathbf{L}_{\mathbf{g}} \\
{[\mathbf{n m}]}\end{array}$ & Channel & $\begin{array}{c}f_{\boldsymbol{T}} \\
{[\mathbf{G H z}]}\end{array}$ & $\begin{array}{c}f_{\text {MAX }} \\
{[\mathbf{G H z}]}\end{array}$ & $\begin{array}{c}\max \boldsymbol{g}_{\boldsymbol{m}} \\
{[\mathbf{m S} / \mathbf{m m}]}\end{array}$ & $\begin{array}{c}\mathbf{I}_{\mathbf{D S S}} \\
{[\mathbf{m A} / \mathbf{m m}]}\end{array}$ & $\begin{array}{c}\mathbf{V}_{\text {BD }} \\
{[\mathbf{V}]}\end{array}$ & Ref. \\
\hline Chalmers & $\mathrm{InP}$ & 130 & $\mathrm{In}_{0.65} \mathrm{Ga}_{0.35} \mathrm{As}$ & 210 & 380 & 1400 & 800 & & {$[4]$} \\
NGC & $\mathrm{InP}$ & 35 & $\mathrm{In}_{0.75} \mathrm{Ga}_{0.25} \mathrm{As}$ & $>500$ & $>500$ & 2300 & & 2.5 & {$[5]$} \\
ETH & $\mathrm{InP}$ & 100 & $\mathrm{In}_{0.68} \mathrm{Ga}_{0.32} \mathrm{As}$ & 270 & 350 & 1100 & 600 & & {$[6,7]$} \\
IAF & $\mathrm{GaAs}$ & 35 & $\mathrm{In}_{0.53} \mathrm{Ga}_{0.47} \mathrm{As}$ & 515 & $>1000$ & 2500 & 1600 & 4 & {$[9]$} \\
OMMIC & $\mathrm{GaAs}$ & 70 & $\mathrm{In}_{0.7} \mathrm{Ga}_{0.3} \mathrm{As}$ & 300 & 350 & 2500 & 600 & $3(\mathrm{G}-\mathrm{D})$ & {$[10]$} \\
BAE & $\mathrm{GaAs}$ & 50 & $\mathrm{In}_{0.8} \mathrm{Ga}_{0.2} \mathrm{As}$ & $>200$ & $>200$ & 2100 & 780 & $4(\mathrm{G}-\mathrm{D})$ & {$[11]$} \\
\hline
\end{tabular}

\section{Design Challenges and Solutions}

Designing an mmw-LNA consists of substantiating a viable solution considering the variety of requirements to be tackled.

Technology is the first issue to be investigated, and some indications have already been provided in the previous Section 2. A very basic (oversimplifying) guideline could be to select InP for the systems where noise figure is the key requirement and reliability-repeatability-cost is not a great concern. Consequently, InP is suitable for radio astronomy and, more generally, all those scientific instruments requiring very high sensitivity. Conversely, GaAs should be employed in those applications were reliability-repeatability-cost is a major system requirement together with the ability of processing medium power signals.

Considering a bottom-up approach, the topics to address are device (bias point and feedback), propagation medium, and finally circuit topology. This design flow is adopted when-for some reason-there is a predefined constraint on the adopted technology, device geometry, and so on. The goal of this approach is to obtain the "best possible" LNA in the framework of the given constraints. On the other hand, a "top-down" approach starts from the analysis of chip-level requirements (noise figure, gain, DC power consumption, port matching, etc.). The designer consequently determines technology, topology, and device in order to fulfil the chip-level requirements. It is worthwhile noting that both procedures are circular rather than straightforward. In other words, some design choice performed in a later stage may affect a previous step, causing one to go back and adjust a parameter decided previously. 
Anyhow, the necessary design steps are similar in both cases and only the order in which they are investigated is changed. In the following, a deeper insight of all related aspects for designing mmw-LNA is provided.

\subsection{Active Device: Geometry, Bias Point, and Feedback}

Accurate device modelling is crucial to increase the chance of obtain a first attempt pass design. Usually devices are characterized linearly up to $100 \mathrm{GHz}$ and for noise at $50 \mathrm{GHz}$. The model is extrapolated above this frequency and some deviations from real behavior must be accounted for. Another issue concerns de-embedding procedure. The device is probed through a coplanar interface (balanced signal) while the model is provided with an accessible source terminal. Standard de-embedding procedures can be profitable applied up to $50 \mathrm{GHz}$, but above this frequency, some additional uncertainties occur. Unfortunately, these aspects are outside the designer's reach, and he must rely on the models supplied by the technology provider.

\subsubsection{Device Geometry}

The selection of an appropriate gate width for a transistor is an essential part of a low-noise amplifier design flow. This is performed by first selecting an optimum unit gate width for a single finger and then placing these fingers in parallel to form a transistor. Apart from differences because of distributed effects of inter-connects, altering the number of fingers does not affect the gain or minimum noise of the transistor. Therefore, changing the number of fingers can be used to select appropriate device impedances for matching and the output power capability of the transistor. At millimeter-wave, an optimum total periphery (number of fingers multiplied by unit gate width) for low-noise performance in a common-source topology is around $50-100 \mu \mathrm{m}$. The number of fingers is typically 2 or 4 . A higher number of fingers would involve higher parasitic reactance, making the device impractical for use above $50 \mathrm{GHz}$.

\subsubsection{Optimum Bias Point}

Transistor performance, and in particular its gain vs. NF trade-off, greatly depends on the bias point. In fact, $F_{\min }$ is directly proportional to the drain current Id through Pospieszalski's equation:

$$
F_{\min } \approx 2 \frac{f}{f_{T}} \sqrt{R_{t} T_{g} G_{d s} T_{d}}
$$

In Equation (1), $f$ is the frequency of operation, $f_{T}$ is the transistor cut-off frequency at the selected bias point, $R_{t}$ is the gate resistance, $T_{g}$ is the ambient temperature, $G_{d s}$ is the transistor output conductance, and $T_{d}$ the transistor channel temperature. Keeping in mind that the channel temperature $T_{d}$ is proportional to the drain current Id in the HEMT. High-frequency operation is obtained when the device's current gain cut-off frequency $\left(f_{T}\right)$ is high ( $\left.>500 \mathrm{GHz}\right) . f_{T}$ is equal to $g_{m} / 2 C_{g s}$, where $g_{m}$ is the trans-conductance and $C_{g s}$ the gate-source capacitance. Consequently, HEMTs with a high trans-conductance at a low bias current are preferred to achieve low-noise performance.

In low-noise applications the transistor is biased at a low-noise/medium-gain operating point, which typically corresponds to $15 \%-20 \%$ of $I_{D S S}$, that is the transistor maximum current. As an example, Figure 3 reports the minimum noise figure $\left(\mathrm{NF}_{\min }\right)$ and associated gain at $30 \mathrm{GHz}$ as a function of drain current density $\mathrm{I}_{\mathrm{D}}(\mathrm{mA} / \mathrm{mm})$ of a two finger $50 \mu \mathrm{m}$ gate width GaAs mHEMT biased at $\mathrm{V}_{\mathrm{DS}}=1.0 \mathrm{~V}$ in OMMIC's D007IH technology. As stated before, there is an optimum bias for noise (at $20 \%$ of $\mathrm{I}_{\mathrm{DSS}}$ ) and optimum bias for gain (at $80 \%$ of $\mathrm{I}_{\mathrm{DSS}}$ ). 


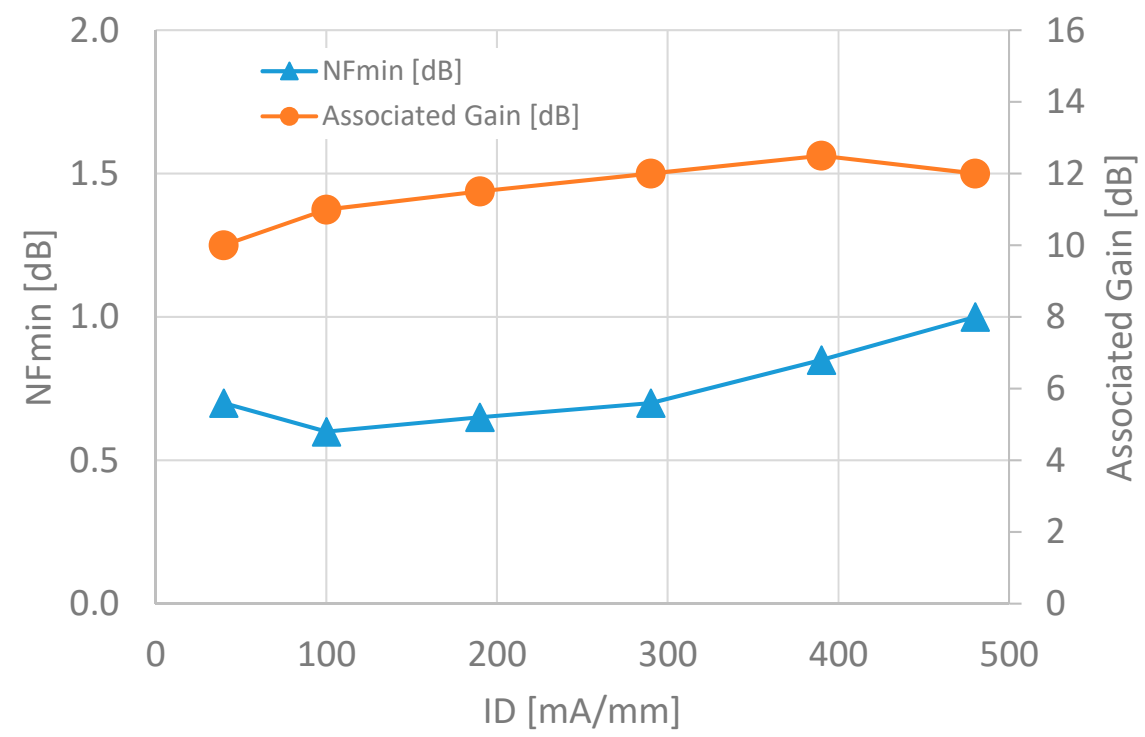

Figure 3. Noise figure (NF) and associated gain at $30 \mathrm{GHz}$ of a $50 \mu \mathrm{m}$ gate width GaAs mHEMT in OMMIC's D007IH technology.

\subsubsection{Source Degenerative Feedback}

This technique, applicable to the common source configuration, consists of inserting an inductive dipole between the FET's source terminal and ground. This technique is applied for a variety reasons, as follows. First, it lowers the gain of the transistor allowing a wider bandwidth operation. Second, it enables simultaneous signal and noise matching (SSNM) [12], which is very important since, in general for low-noise devices, the optimum impedances for matching and noise are far from each other. This point also enables a wider bandwidth operation. Third, the gain reduction improves the transistor's stability, at least in the operating bandwidth.

At lower microwave frequencies, the inductive dipole is realized through a spiral inductor. As the frequency increases, a short and thin microstrip line replaces the spiral inductor. At very high frequencies, the parasitic inductance of the via-hole to ground through the substrate is often enough to obtain the desired effect. In multi-stage amplifiers, as occurs in mmw-LNAs, there are design guidelines that aid the designer in selecting the inductance value for each stage given a gain/stability constraint, with the aim to obtain an input and output match as close as possible to $50 \Omega$ [13].

\subsection{Propagation at Millimeter-Wave on-Chip}

Microstrip has an elegant simplicity to it, which makes it easier to fabricate and even easier to model via computer than coplanar waveguide or its grounded counterpart. With their strong ground structure, coplanar waveguide circuits are capable of lower-loss performance at much higher frequencies than microstrip MMICs and offer great potential for designs working well into the millimeter-wave frequency range. On the other hand, microstrip is probably the most popular transmission-line format but suffers increased circuit losses into the millimeter-wave frequency range, making the circuit technology less efficient for use at frequencies above $100 \mathrm{GHz}$.

Figure 4 reports commonly used structures for transmission lines at millimeter-wave where also noteworthy geometrical parameters are reported that determine the electrical features of the transmission line, namely characteristic impedance $Z_{0, C}$ and phase constant $\beta$. 


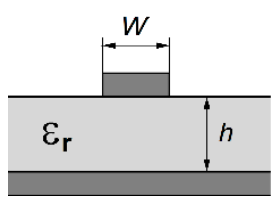

(a)

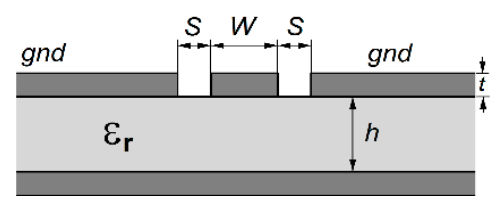

(b)

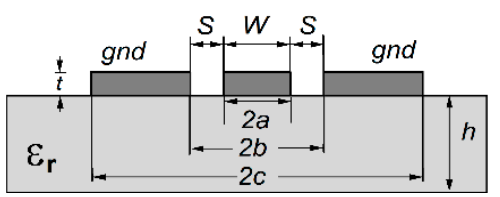

(c)

Figure 4. Microstrip (a), grounded coplanar waveguide (b), and coplanar waveguide (c) structures.

\subsubsection{Microstrip}

Microstrip, as shown in Figure 4a, is the most common configuration in MMIC technology, mainly due to the large availability of electrical models (both active and passive), and it also represents the baseline solution in CAD simulation tools. This choice is reasonable up to $\mathrm{W}$-band (110 GHz), after which a series of critical aspects occur that make this configuration unfeasible. As stated in Section 3.1.3, the parasitic inductance of the via-hole to ground through the substrate may become significant, leading to an unacceptable decrease in the gain of the device. A possible solution to this weakness consists of thinning down the wafer to 50 or even $20 \mu \mathrm{m}$. Although the inductive effect reduced, the wafer becomes difficult to handle due to the reduced thickness. In any case, resonant modes across the substrate and high-order modes appear when the wavelength of the signal becomes comparable to substrate thickness, and ultimately limit the usable frequency range of the microstrip structure. The dielectric constants of InP and GaAs are quite similar: Respectively, 12.4 and 12.9. The W/h ratio for $50 \Omega$ characteristic impedance in both cases is about $75 \%$. Therefore, a $50 \Omega$ microstrip line will have a width of about $75 \mu \mathrm{m}$ on a $100 \mu \mathrm{m}$ thick GaAs or InP substrate. A simplified relation between characteristic impedance the a microstrip transmission line and its W/h ratio is shown in Figure 4a, and frequencies are provided in Equation (2). This relation is applicable to GaAs and InP substrates at millimeter-wave and is valid for $0.1<\mathrm{W} / \mathrm{h}<3$.

$$
Z_{0, C} \approx 44-23 \ln \left(\frac{\mathrm{W}}{\mathrm{h}}\right)[\Omega]
$$

Figure 5 contains the plot of the relationship expressed in Equation (2).

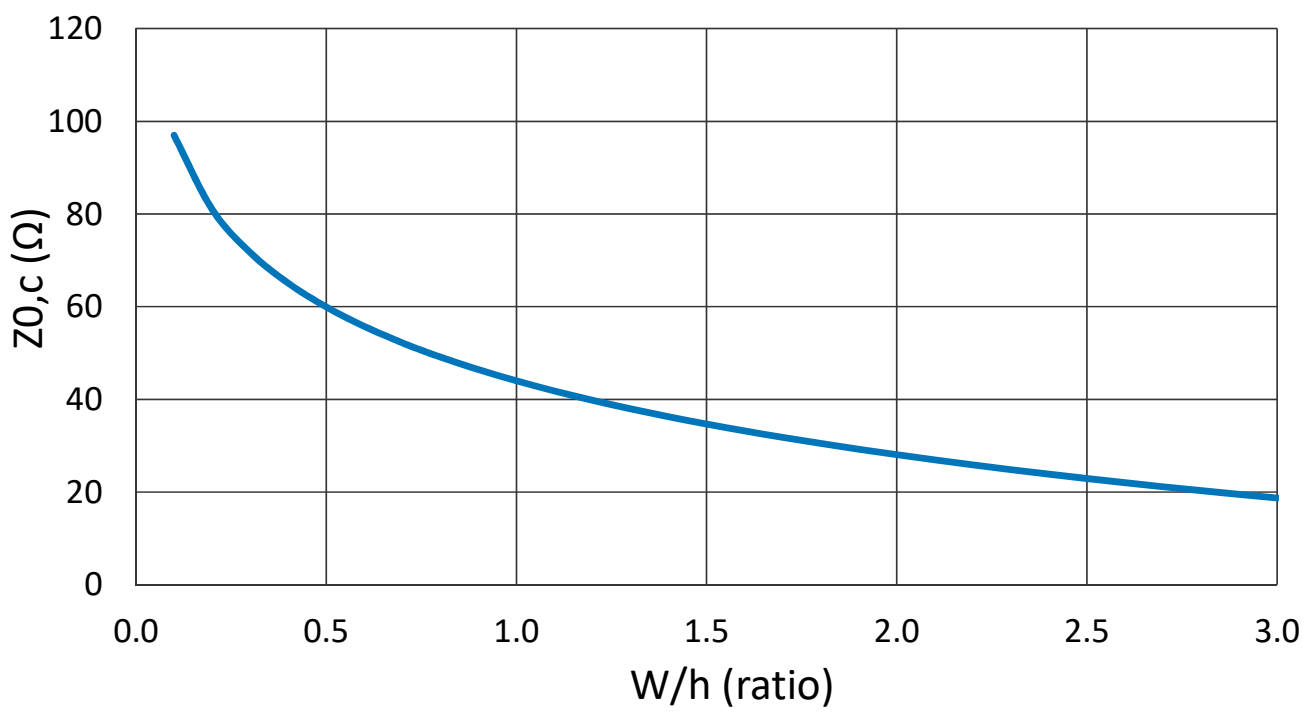

Figure 5. Characteristic impedance vs. W/h ratio for a GaAs or InP microstrip line at millimeter-wave frequencies. 


\subsubsection{Coplanar Waveguide (Grounded or Not)}

Coplanar waveguide (CPW) configuration in Figure $4 b, c$ is particularly helpful in order to circumvent the criticalities sketched in the previous section. The presence of cold conductors on the same plane of the signal line introduces much less losses and couplings through the substrate, allowing the use at higher frequencies. In fact, the parasitic inductance to ground for shunt elements is much lower for CPW, compared to microstrip applications. This is because the RF ground is very close to the transmission line, and there is no need to drill a via-hole through the substrate for ground connection. This, in turn, eases manufacturing issues. However, this solution is all but effortless: The two lateral ground planes make the realization of circuits based on this transmitting structure much more complex, both for the higher bigger overall dimensions and for the need to impose them the same voltage at every section. Furthermore, CAD tools are less oriented towards this configuration and reliable electrical models are often lacking. The same consideration holds for active device models provided by the foundry.

Ground plane is mandatory when the MMIC is going to be mounted in a metallic carrier, which is often the case at millimeter-wave, and the second ground plane is placed on the opposite side of the dielectric. This variant of coplanar waveguide is known as grounded coplanar waveguide (GCPW) and is schematically depicted in Figure $4 \mathrm{~b}$. For a given line impedance, there is, in theory, an infinite number of solutions for the geometry of a GCPW line. In fact, while H appearing in Equation (2) is fixed by the technology provider, in CPGW, the impedance is synthesized by appropriately determining the ratio of W/S, since both width (W) and spacing (S) are a free design variable. The only limit is feasible values for $\mathrm{S}$ above a minimum value specified by the foundry rules.

A simplified relation between characteristic impedance of the GCPW transmission line and its W/S ratio, valid at millimeter-wave frequencies, is provided in Equation (3).

$$
Z_{0, C} \approx 55-14 \ln \left(\frac{W}{S}\right)[\Omega]
$$

This relation is applicable to GaAs and InP substrates and is valid for $0.1<\mathrm{W} / \mathrm{S}<10$ and $5 \mu \mathrm{m}<$ $\mathrm{S}<40 \mu \mathrm{m}$. In order to obtain feasible values of $\mathrm{W}$, larger values of $\mathrm{S}$ are used to synthesize higher characteristic impedance while smaller values of $S$ to obtain lower characteristic impedance. Figure 6 contains the plot of the relationship expressed in Equation (3). In this case, the curves are parametrized for several values of $S$ in the range from $5 \mu \mathrm{m}$ to $40 \mu \mathrm{m}$. The curves are validated for substrate thickness (h) between 50 and $100 \mu \mathrm{m}$.

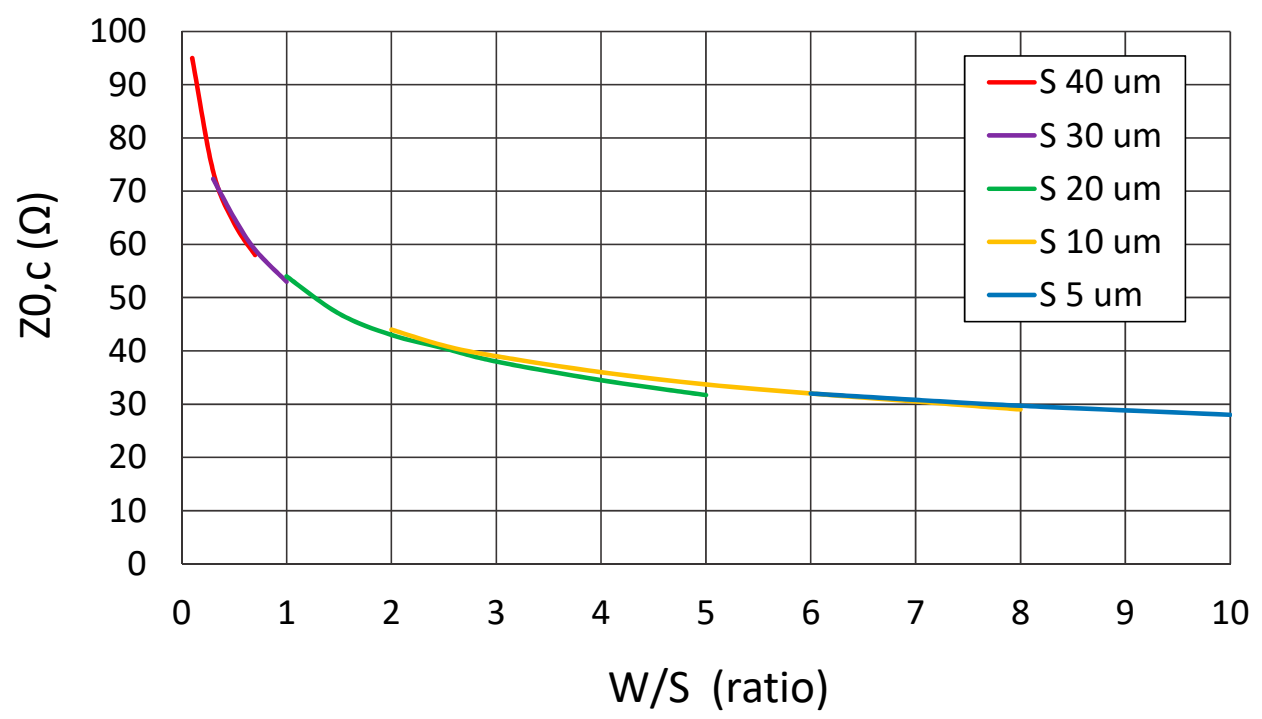

Figure 6. Characteristic impedance vs. W/S ratio for a GaAs or InP grounded coplanar waveguide (GCPW) line at millimeter-wave frequencies. 


\subsection{Circuit Topologies}

Circuit topology is selected to fulfil some system architectural constraint or chip-level requirement. The trade-off to be performed is between circuit complexity and mmw-LNA performance. As the requirements between more stringent, for example ultra-wide operating bandwidth and adequate $(>10 \mathrm{~dB})$ input/output return loss, then circuit complexity increases. Fortunately, very low noise figure can be fulfilled even with the simplest circuit topology, as expressed in the following sections.

\subsubsection{Single Ended}

Single ended is by far the most employed topology in mmw-LNA since it is relatively easy to synthesize. At high-operating frequency, a sensible design strategy consists of keeping circuit complexity at the lowest possible level. Single-ended topology consists of cascading a certain number of common source (CS) amplifying stages to obtain the prescribed gain value, obviously within the limitation of a feasible number of stages. A simplified schematic of an $\mathrm{N}$-stage $(\mathrm{N}=4)$ single-ended amplifier is shown in Figure 7.

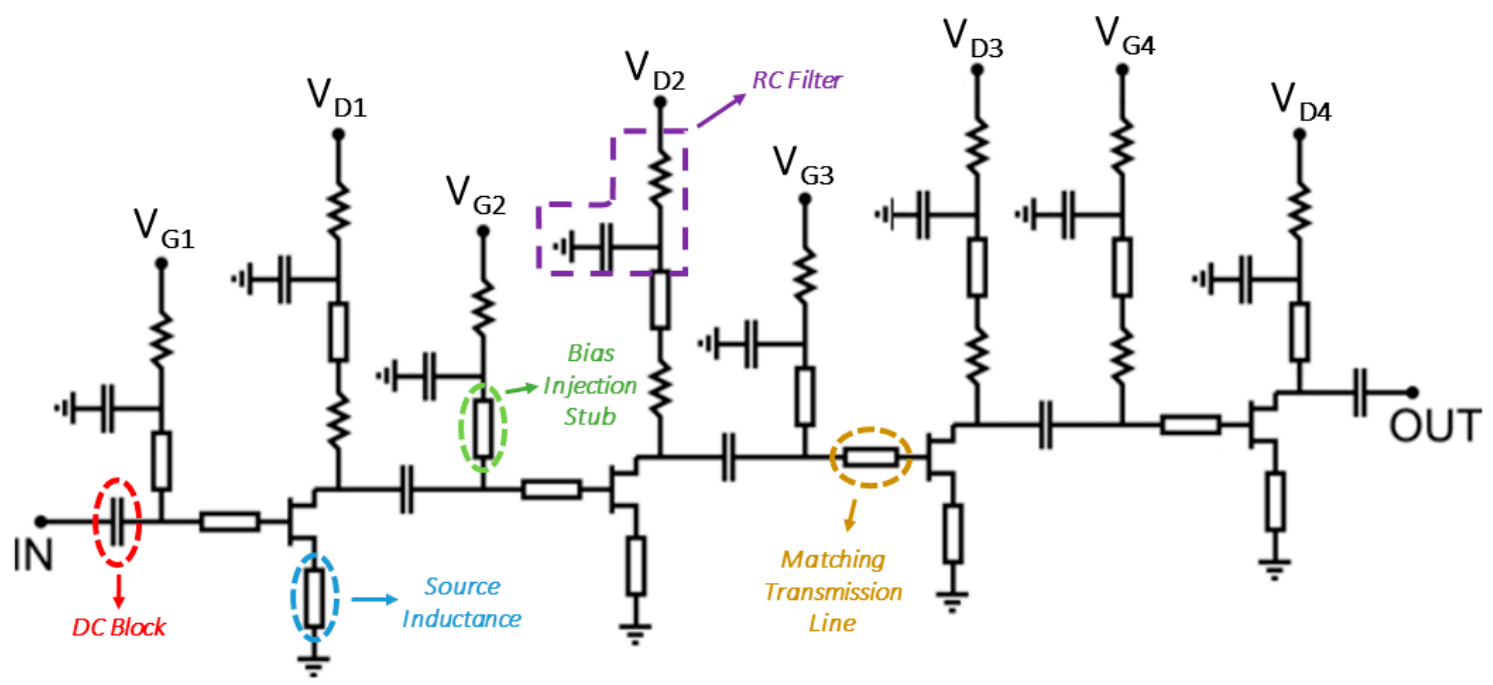

Figure 7. Schematic of a four-stage single-ended millimeter-wave low-noise amplifiers (mmw-LNA).

Once the active device has been selected, biased cured by feedback, as described in Section 3.1, the following step consists of determining the number of necessary stages. These usually vary from 3 to 5 as a function of the operating frequency and technology performance. Usually, three stages are sufficient to reach an adequate gain level $(>20 \mathrm{~dB})$ at lower millimeter-wave frequencies (i.e., $<70 \mathrm{GHz}$ ) [14]. When the frequency increases, then it is not uncommon to find mmw-LNA with more than four stages [15].

The final step of the design consists of appropriately sizing the components that appear in Figure 7. Series and shunt transmission lines are used for noise/signal matching (at RF) and transistor biasing (at DC). Series DC-block capacitors are inserted also for matching purposes and their value rarely exceeds $0.3 \mathrm{pF}$, often even less as the frequency increases. Design practice and analysis of open literature lead to the conclusion that external DC blocking capacitors-i.e., the ones at the LNA's I/O ports-are larger than the capacitors inserted for inter-stage matching and DC blocking embedded in the LNA. The latter are often half the size or even less of the external capacitors. This is because I/O capacitors are directly linked to the LNA's I/O matching, while the internal capacitor's value is chosen to fulfil some gain over frequency requirement and effects the LNA's I/O match less. External capacitors are in the range of 0.1 to $0.3 \mathrm{pF}$, while the internal ones can be less than $0.1 \mathrm{pF}$. Electro-magnetic simulations become mandatory at this point since the capacitance of the internal DC-blocks is comparable to other parasitic capacitance inside the circuit. Finally, resistors and capacitors are used to filter out unwanted 
signals that may be present in the bias supplies and moreover provide the ohmic losses to stabilize the device at lower frequencies. Please note that in the last stages, resistors are also inserted close to the active device. This technique improves device stability at lower frequencies at the expense of higher stage NF. This is acceptable when the gain of the preceding stages in enough to conceal the higher noise contribution coming from the stages containing the resistors.

\subsubsection{Cascode}

Cascode topology represents an interesting solution when large operating bandwidth is a design goal in conjunction with low NF and high gain. In this topology, a common source stage is cascaded with a common gate stage that acts as a wideband low-input impedance buffer stage for the preceding stage. A simplified schematic of a cascode cell is depicted in Figure 8.

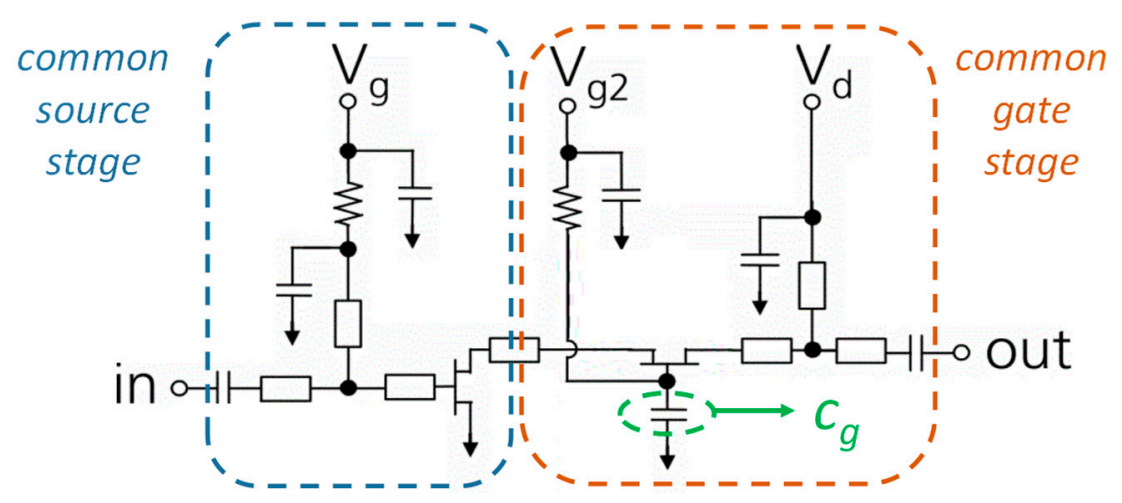

Figure 8. Schematic of a cascade mmw-LNA.

Unfortunately, circuit complexity, with respect to single-ended topology, is somewhat increased for the following reasons. First, the DC drain voltage, Vd in Figure 8, is divided across the two transistors and, moreover, the current flow in the two transistors is the same by design. Consequently, a detailed DC analysis needs to be carried out. Second, the gate terminal (Vg2) of the common gate stage cannot be DC-grounded but needs to be biased at slightly less half the value of Vd. Consequently, the gate is AC grounded-trough capacitor $\mathrm{Cg}$ - and this poses some limitations on the practical operating bandwidth. The technique involves choosing a small and appropriate $\mathrm{Cg}$ value to present an optimum load to the drain of the common source transistor of the cascode. This method departs from the conventional practice of choosing a large $\mathrm{Cg}$ to provide good $\mathrm{AC}$ grounding to the common gate transistor. Typical values of $\mathrm{Cg}$ at millimeter-wavelength is around $0.1 \mathrm{pF}$. Occasionally, a parallel-parallel feedback synthesized through a series R-C connecting the transistor's drain and gate terminals is applied to the common gate transistor to improve its stability and obtain an even greater bandwidth of operation.

\subsubsection{Balanced}

Balanced topology represents an interesting solution when adequate values of input and output return loss are required over a very large operating bandwidth. The main downside of this topology is the ohmic losses introduced by the input power splitter that directly affect the mmw-LNA's NF. Another negative side effect is the size of this circuit, which is practically double the single-ended version. Apart from adequate return loss over a wide operating frequency, this topology has another benefit such as higher power handling capability, since the incident RF power is halved at the input before the two LNA stages. A simplified description is reported in Figure 9. 


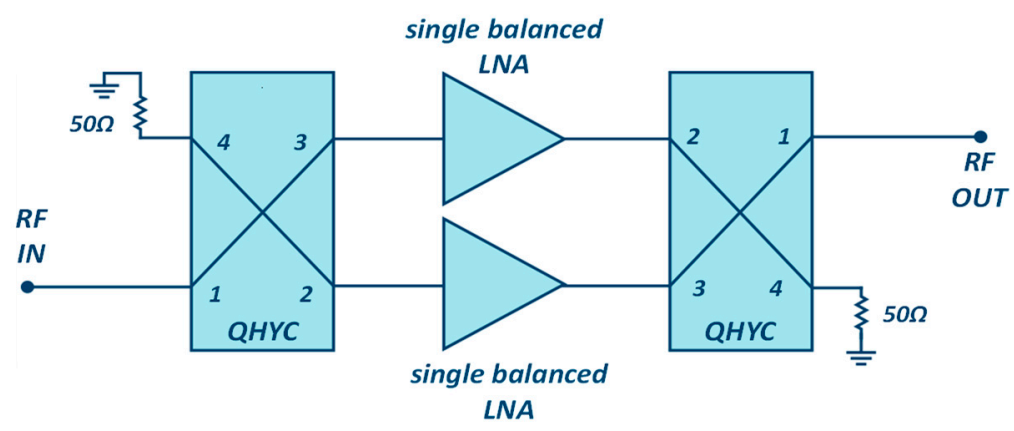

Figure 9. Balanced LNA schematic.

The single balanced LNA stages are synthesized as described in Section 3.1.1., while the input and output power splitter/combiner are quadrature hybrid couplers (QHYC). When used as a divider, the signal is fed at port 1 . Consequently, the signals at port 2 and port 3 have ideally identical power ( $3 \mathrm{~dB}$ less than at the input) and are out phased by $90^{\circ}$. Port 4 is isolated, at least ideally, and terminated on the reference impedance $(50 \Omega)$. When used as a combiner, ports 2 and 3 act as input ports while port 1 is the output port. Since the signals incident at port 2 and port 3 are appropriately out-phased, the signals are coherently summed at port 1 . Once again, port 4 is terminated on the reference impedance $(50 \Omega)$ and the two incoming signals are cancelled since they are practically out phased by $180^{\circ}$. An example of balanced mmw-LNAs operating at W-band is reported in [16,17]. It is interesting to note that the two realizations only have the circuit topology in common. In fact, while [16] is a three-stage circuit realized in microstrip InP technology, [17] is a four-stage realized on GaAs substrate in coplanar-waveguide.

\section{Recent State-of-the-Art Implementations}

The design solutions outlined in this paper where used to synthesize an mmw-LNA operating in V-band, and more precisely in the $59-66 \mathrm{GHz}$ frequency range. A drawback of V-band ( $50-75 \mathrm{GHz})$ is the high attenuation around $60 \mathrm{GHz}$, due to the absorption of oxygen molecules in the atmosphere, making it impractical for telecommunications that include a terrestrial segment. On the other hand, such absorption is not present in outer space, and V-band represents an interesting option for high-data rate inter-satellite link (ISL) communications.

The mmw-LNA performance requirements (average NF $<2 \mathrm{~dB}$ and linear-gain $>20 \mathrm{~dB}$ ) are challenging considering the working frequency and the limitation of using space-qualified industrial grade technology. Given these constraints, the choice fell upon OMMIC's D007IH process. A representative device of this technology features around $1.2 \mathrm{~dB}$ minimum noise figure $\left(\mathrm{NF}_{\min }\right)$ at $60 \mathrm{GHz}$, with $10 \mathrm{~dB}$ associated gain [10].

A single-ended three-stage LNA topology was chosen given the capability of the selected technology and the relatively small bandwidth requirements, which represents a satisfactory trade-off to simultaneously meet the electrical requirements, size, and circuit complexity with the consequent reliability of the circuit. An active device geometry of $4 \times 12.5 \mu \mathrm{m}$ was chosen for all stages. A low-noise operating point was selected: $\mathrm{V}_{\mathrm{DS}}=1.0 \mathrm{~V}$ and $\mathrm{I}_{\mathrm{D}}=10 \mathrm{~mA}$, and the small-signal and noise model was extracted in-house.

Inductive source degeneration technique has been applied to every stage, as described in Section 3.3.1, to ease the unavoidable compromise between low-noise and gain.

Figure 10 reports the micro-photograph of the realized mmw-LNA and the measured S-parameters that are in-line with the proposed requirements. Preliminary noise characterization of the LNA has been carried out showing the circuit meets the prescribed requirement: NF $<2 \mathrm{~dB}$. 


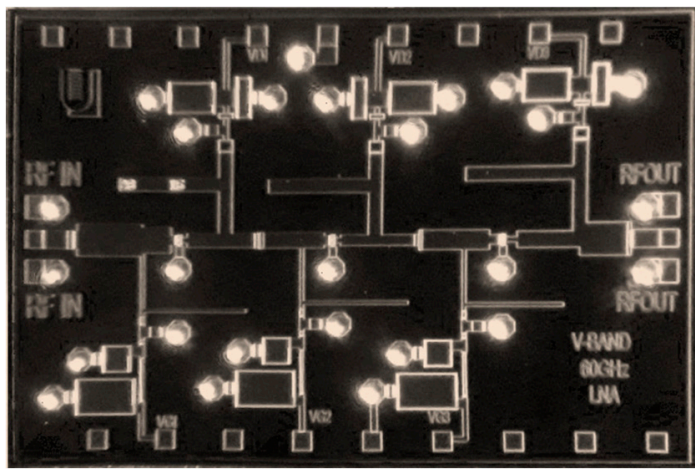

(a)

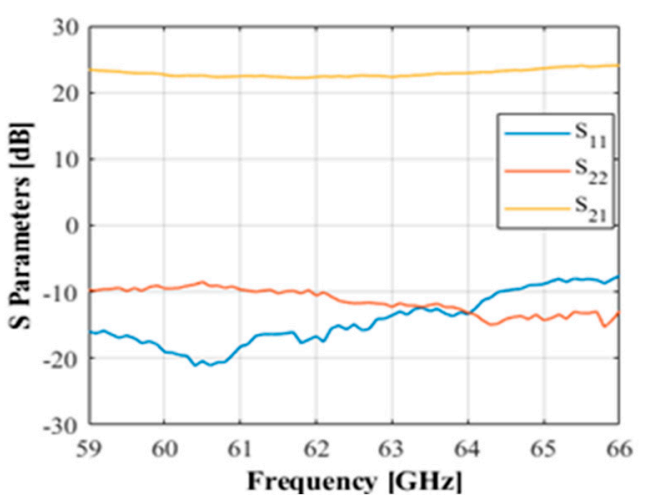

(b)

Figure 10. Realized V-band LNA monolithic microwave integrated circuit (MMIC). (a) Microphotograph, chip size is $(3.0 \times 2.0) \mathrm{mm}^{2}$ and $(\mathbf{b})$ measured S-parameters in the $59-66 \mathrm{GHz}$ bandwidth.

Stability has been analyzed from 1 to $70 \mathrm{GHz}$ using the geometric stability factor of a two-port at its source and load terminals. This value is always greater than unity over the entire frequency range and greater than 1.2 from 23 to $65 \mathrm{GHz}$.

Regarding the LNA's non-linear characteristics, the expected output power at $1 \mathrm{~dB}$ compression point is $+5 \mathrm{dBm}$, while the output third order intercept point is $+15 \mathrm{dBm}$.

A summary of the key-parameters-operating frequency, average in-band gain, noise figure at room temperature, equivalent noise temperature $\left(\mathrm{T}_{\mathrm{eq}}\right)$ in cryogenic environment, technology, and propagation structure (GCPW or microstrip) - for recently published mmw-LNAs in open literature is presented in Table 2.

Data are also plotted in Figure 11, to evaluate the trend vs. frequency and infer an outlook on operation beyond $300 \mathrm{GHz}$.

Table 2. Performance summary of published LNA works.

\begin{tabular}{|c|c|c|c|c|c|c|c|c|c|c|}
\hline $\begin{array}{l}\text { IEEE } \\
\text { Band }\end{array}$ & $\begin{array}{c}\mathbf{f}_{\min } \\
{[\mathrm{GHz}]}\end{array}$ & $\begin{array}{c}\mathbf{f}_{\max } \\
{[\mathrm{GHz}]}\end{array}$ & $\underset{\text { [dB] }}{\text { Avg Gain }}$ & $\begin{array}{c}\mathrm{NF}[\mathrm{dB}] \\
@ \mathrm{~T}_{\mathrm{amb}}\end{array}$ & $\begin{array}{c}\text { Cryo } \\
\mathrm{T}_{\text {eq }}[\mathrm{K}]\end{array}$ & Technology & $\begin{array}{l}\text { GCPW } \\
\text { or MS }\end{array}$ & Year & Author & Ref. \\
\hline$X$ to $U$ & 8 & 48 & 25 & - & $\begin{array}{l}25 \\
20\end{array}$ & $\begin{array}{l}\text { GaAs } 70 \mathrm{~nm} \\
\text { InP } 35 \mathrm{~nm}\end{array}$ & MS & 2019 & Velazco & [18] \\
\hline $\mathrm{Ka}$ & 22 & 36 & 35 & - & 12 & InP 130 nm & MS & 2015 & Nilsson & [19] \\
\hline $\mathrm{Ka}$ & 24 & 40 & 40 & 1.5 & 13 & InP 35 nm & MS & 2013 & Schleeh & [20] \\
\hline $\mathrm{Ka}$ & 26 & 40 & 28 & 1.7 & 18 & GaAs $70 \mathrm{~nm}$ & MS & 2016 & Collantes & [21] \\
\hline $\mathrm{Ka}$ & 26 & 40 & 23 & 1.5 & 11 & InP 100 nm & MS & 2006 & Tang & [22] \\
\hline $\mathrm{U}$ & 40 & 51 & 16 & 2 & - & GaAs $100 \mathrm{~nm}$ & MS & 2016 & Pantoli & [24] \\
\hline $\mathrm{U}$ & 47 & 52 & 17 & 2 & - & GaAs $70 \mathrm{~nm}$ & MS & 2018 & Ciccognani & [25] \\
\hline V & 59 & 66 & 22 & 1.9 & - & GaAs $70 \mathrm{~nm}$ & MS & 2019 & Longhi & This Work \\
\hline $\mathrm{V}$ to $\mathrm{D}$ & 60 & 124 & 22 & 1.9 & 34 & GaAs $50 \mathrm{~nm}$ & GCPW & 2016 & Kotiranta & [26] \\
\hline W & 60 & 120 & 25 & 1.9 & - & GaAs $50 \mathrm{~nm}$ & GCPW & 2019 & Thome & [17] \\
\hline $\mathrm{V}$ to $\mathrm{W}$ & 67 & 90 & 28 & 2.5 & 30 & InP 35 nm & MS & 2009 & Bryerton & [27] \\
\hline W & 71 & 86 & 20 & 2.3 & - & InP 70 nm & MS & 2018 & Ciccognani & {$[32]$} \\
\hline W & 75 & 105 & 29 & 3.0 & 25 & InP $35 \mathrm{~nm}$ & MS & 2012 & Samoska & [33] \\
\hline W & 75 & 105 & 25 & 2.7 & - & $\mathrm{InP} 70 \mathrm{~nm}$ & MS & 2008 & Ciccognani & [34] \\
\hline W to $D$ & 75 & 116 & 25 & 2.5 & 25 & InP $130 \mathrm{~nm}$ & MS & 2013 & Varonen & [35] \\
\hline W & 80 & 100 & 30 & 1.9 & - & InP 100 nm & MS & 2014 & Farkas & [15] \\
\hline W & 80 & 100 & 12 & 5 & - & GaAs $100 \mathrm{~nm}$ & GCPW & 2014 & Bessemou. & [36] \\
\hline $\mathrm{E}$ & 81 & 86 & 20 & 1.7 & - & InP 35 nm & MS & 2016 & Estella & [16] \\
\hline $\mathrm{D}$ & 115 & 160 & 20 & 5 & - & GaAs $40 \mathrm{~nm}$ & GCPW & 2017 & Cleriti & [37] \\
\hline $\mathrm{D}$ & 120 & 170 & 18 & 3.3 & 46 & InP 35 nm & MS & 2013 & Larkoski & [38] \\
\hline D to $G$ & 155 & 190 & 14 & 3.7 & - & InP 35 nm & GCPW & 2008 & Kangaslahti & [39] \\
\hline D to $G$ & 160 & 190 & 24 & 4 & - & GaAs $35 \mathrm{~nm}$ & GCPW & 2015 & Moschetti & [40] \\
\hline G & 225 & 285 & 30 & 6 & - & GaAs $35 \mathrm{~nm}$ & GCPW & 2014 & Tessmann & [41] \\
\hline
\end{tabular}




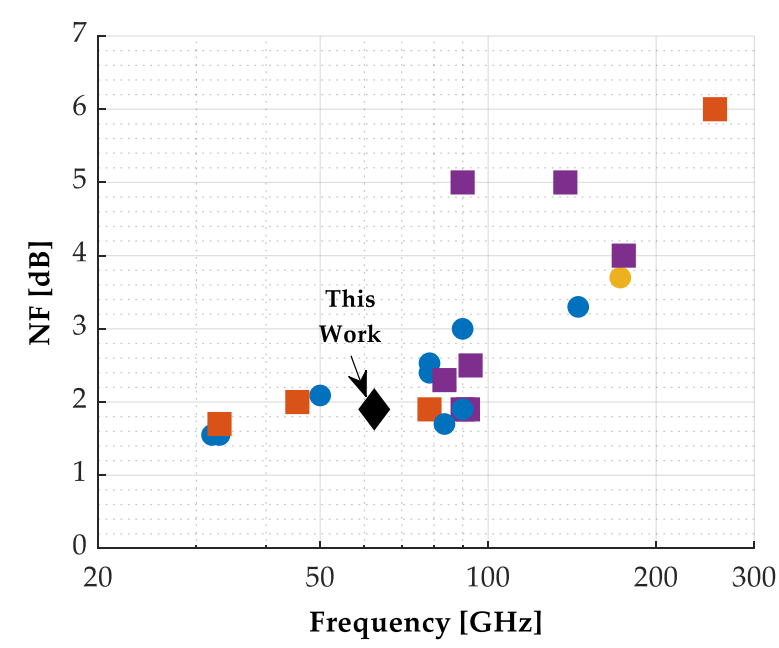

(a)

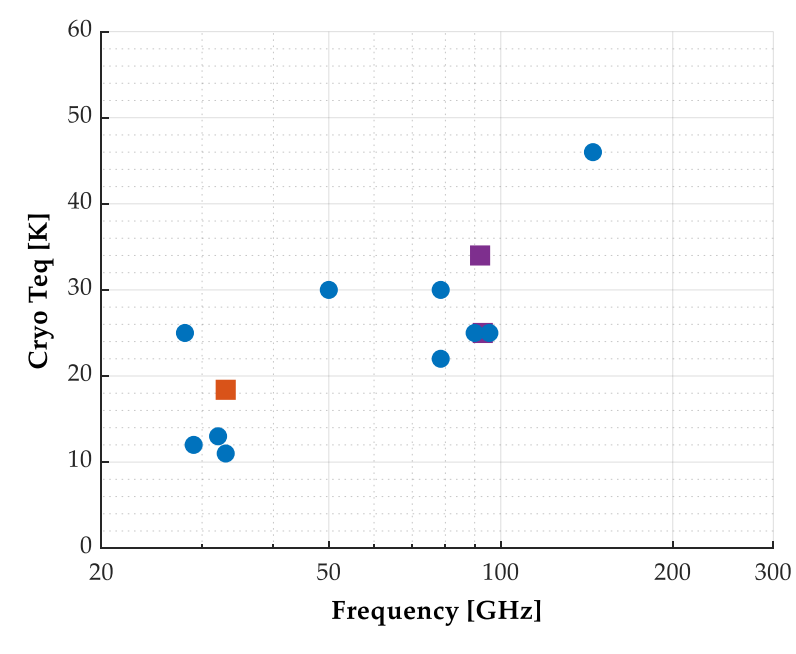

(b)

Figure 11. Noise figure at ambient temperature (a) and equivalent noise temperature in cryogenic environment (b) versus frequency of the works summarized in Table 2. LNAs are differentiated by technology and guiding structure. In detail: GaAs in microstrip (orange squares), GaAs in coplanar waveguide (purple squares), InP in microstrip (blue circles), and InP in coplanar waveguide (yellow circles). The black diamond represents the V-band LNA presented in this work and shown in Figure 10.

The two plots presented in Figure 11 illustrate state-of-the-art NF and $\mathrm{T}_{\text {eq }}$ performance below $3 \mathrm{~dB}$ and $35 \mathrm{~K}$ up to $100 \mathrm{GHz}$. Microstrip InP technology is the most common and reveals the best performance in the table, with MMICs exhibiting minimum NF below $2 \mathrm{~dB}$ even in the 80-90 GHz band. The presented V-band LNA features $1.9 \mathrm{~dB}$ average NF, thus belonging to the state-of-the-art picture.

Regarding room temperature operation, state-of-the art LNAs operating above $80 \mathrm{GHz}$ demonstrate noise figure performance vs. operating frequency quantified through relationship:

$$
N F_{L N A} \approx f_{0} \times N F_{0}
$$

where $f_{0}$ is the operating frequency, expressed in $\mathrm{GHz}$, while $N F_{0}$ is approximately equal to $0.02 \mathrm{~dB} / \mathrm{GHz}$. In fact, LNAs operating around $100 \mathrm{GHz}$ demonstrate $2 \mathrm{~dB} \mathrm{NF}, 4 \mathrm{~dB} \mathrm{NF}$ at $200 \mathrm{GHz}$ and $6 \mathrm{~dB}$ at $300 \mathrm{GHz}$. It is interesting to note that such a linear relationship is verified up to $650 \mathrm{GHz}$ [42].

Similar considerations apply for the equivalent noise temperature measured in a cryogenic environment. For this feature, the gradient of the linear relationship in approximately $0.3 \mathrm{~K} / \mathrm{GHz}$. In this case, results are more spread since the physical temperature at which the MMIC is cooled down influences the equivalent noise temperature. As anticipated in Section 3.2, MMICs operating above W-band are synthesized using a coplanar waveguide structure, while the microstrip is the preferred choice up to W-band. Finally, the vast majority of the reported MMICs feature a single balanced topology, demonstrating it is a viable solution to obtain low noise and high gain at millimeter-wave.

\section{Future Trends and Emerging Technologies at Millimeter-Wave}

GaAs and InP will remain the principal semiconductor technologies for very low-noise applications in the future, but the advent of gallium nitride $(\mathrm{GaN})$ or even silicon germanium-based CMOS will modify the scenario within the next 5 to 10 years. GaN has the advantage of providing interestingly low-noise performance in conjunction with very high-power handling capability [43]. It could become the reference semiconductor for those applications where linearity is a concern together with the robustness to strong interference signal.

Silicon-germanium-based BiCMOS remains somewhat behind for noise performance but has on its side its relatively inexpensive production process that makes it attractive for large-volume 
applications. In this context, transistors have been realized that exhibit $f_{T}$ and $f_{M A X}$ in the order of $300 \mathrm{GHz} / 500 \mathrm{GHz}$.

Further improvements rely on the continuous scaling of the transistor gate length moving towards $10 \mathrm{~nm}$ gate length or even shorter devices. Correspondingly, ad-hoc device characterization and modelling will be required to fully exploit device potentials.

Although the topic has not been addressed in this review, packaging at millimeter-wave [44] can provide further advancement. It will enable more compact/lightweight systems to be capable of operating in harsher environments.

\section{Conclusions}

The leading technologies and design solutions to obtain millimeter-wave low-noise amplifiers with solid-state devices are presented in this work. InP HEMTs achieve the best noise figure values reported to date. Analysis has demonstrated that a linear LNA NF versus operating frequency is applicable from around $80 \mathrm{GHz}$ up to $650 \mathrm{GHz}$. Nonetheless, GaAs mHEMTs represent an attractive solution if a (slightly) worse noise behavior is acceptable in exchange for lower cost and higher volume production. In this context, an mmw-LNA operating at V-band has been designed, realized, and tested demonstrating results in-line with the state-of-the-art. Applications for MMIC LNAs at millimeter-wave include radio astronomy, remote sensing, spaceborne communications, short-range high-capacity links, earth science, radar, imaging, vehicle guidance, and security.

Author Contributions: Conceptualization, P.E.L., L.P., and E.L.; resources, S.C and W.C.; data curation, S.C and W.C.; writing-original draft preparation, P.E.L and L.P; writing-review and editing, P.E.L and E.L.; visualization, S.C. and W.C.; supervision, E.L.

Funding: This research received no external funding

Conflicts of Interest: The authors declare no conflict of interest

\section{References}

1. Ciccognani, W.; Limiti, E.; Longhi, P.E.; Renvoise, M. MMIC LNAs for Radioastronomy Applications Using Advanced Industrial $70 \mathrm{~nm}$ Metamorphic Technology. IEEE J. Solid-State Circuits 2010, 45, 2008-2015. [CrossRef]

2. Appleby, R.; Anderton, R.N. Millimeter-wave and submillimeter-wave imaging for security and surveillance. Proc. IEEE 2007, 95, 1683-1690. [CrossRef]

3. Akgiray, A.H.; Weinreb, S.; Leblanc, R.; Renvoise, M.; Frijlink, P.; Lai, R.; Sarkozy, S. Noise measurements of discrete HEMT transistors and application to wideband very low-noise amplifiers. IEEE Trans. Microw. Theory Tech. 2013, 61, 3285-3297. [CrossRef]

4. Schleeh, J.; Alestig, G.; Halonen, J.; Malmros, A.; Nilsson, B.; Nilsson, P.A.; Starski, J.P.; Wadefalk, N.; Zirath, H.; Grahn, J. Ultralow-power cryogenic InP HEMT with minimum noise temperature of $1 \mathrm{~K}$ at $6 \mathrm{GHz}$. IEEE Electron Device Lett. 2012, 33, 664-666. [CrossRef]

5. Sarkozy, S.; Mei, X.; Yoshida, W.; Liu, P.H.; Lee, L.S.; Zhou, J.; Leong, K.; Radisic, V.; Deal, W.; Lai, R. Sub-50nm indium phosphide high electron mobility transistor technology for terahertz monolithic microwave integrated circuits and systems. In Proceedings of the International Conference on Indium Phosphide and Related Materials, Kobe, Japan, 19-23 May 2013; Volume 1, pp. 1-2.

6. Liu, L.; Alt, A.R.; Benedickter, H.; Bolognesi, C.R. InP/GaInAs pHEMT Ultralow-Power Consumption MMICs. In Proceedings of the 2011 IEEE Compound Semiconductor Integrated Circuit Symposium (CSICS), Waikoloa, HI, USA, 16-19 October 2011; pp. 1-4.

7. Liu, L.; Alt, A.R.; Benedickter, H.; Bolognesi, C.R. InP-HEMT X-band Low-Noise Amplifier with Ultralow 0.6-mW Power Consumption. IEEE Electron Device Lett. 2012, 33, 209-211. [CrossRef]

8. Ajayan, J.; Nirmal, D.; Mohankumar, P.; Kuriyan, D.; Fletcher, A.S.A.; Arivazhagan, L.; Kumar, B.S. GaAs Metamorphic High Electron Mobility Transistors for Future Deep. Microelectron. J. 2019, 92, 104604. [CrossRef] 
9. Leuther, A.; Tessmann, A.; Dammann, M.; Massler, H.; Schlechtweg, M.; Ambacher, O. 35 nm mHEMT Technology for $\mathrm{THz}$ and ultra low noise applications. In Proceedings of the International Conference on Indium Phosphide and Related Materials (IPRM), Kobe, Japan, 19-23 May 2013; Volume 2, pp. 1-2.

10. Ciccognani, W.; Colangeli, S.; Serino, A.; Pace, L.; Longhi, P.E.; Limiti, E.; Poulain, J.; Leblanc, R. Comparative noise investigation of high-performance GaAs and $\mathrm{GaN}$ millimeter-wave monolithic technologies. In Proceedings of the 14th European Microwave Integrated Circuits Conference (EuMIC), Paris, France, 29 September-2 October 2019; pp. 1-4.

11. Komiak, J.J.; Smith, P.M.; Duh, K.H.G.; Xu, D.; Chao, P.C. Metamorphic HEMT technology for microwave, millimeter-wave, and submillimeter-wave applications. In Proceedings of the 2013 IEEE Compound Semiconductor Integrated Circuit Symposium (CSICS), Monterey, CA, USA, 13-16 October 2013; pp. 1-4.

12. Colangeli, S.; Longhi, P.E.; Ciccognani, W.; Limiti, E. On the Optimum Noise-Gain Locus of Two-Ports. IEEE Trans. Microw. Theory Tech. 2019, 67, 2284-2290. [CrossRef]

13. Salvucci, A.; Longhi, P.E.; Colangeli, S.; Ciccognani, W.; Serino, A.; Limiti, E. A straightforward design technique for narrowband multi-stage low-noise amplifiers with $\mathrm{I} / \mathrm{O}$ conjugate match. Int. J. RF Microw. Comput. Eng. 2019, 29, e21833. [CrossRef]

14. Varonen, M.; Samoska, L.; Kangaslahti, P.; Fung, A.; Gawande, R.; Soria, M.; Peralta, A.; Lin, R.; Lai, R.; Mei, X.; et al. Cryogenic MMIC low-noise amplifiers for V-band. In Proceedings of the 2017 IEEE MTT-S International Microwave Symposium (IMS), Honololu, HI, USA, 4-9 June 2017; pp. 172-175.

15. Farkas, D.S.; Sarkozy, S.J.; Katz, R. A W-band 100 nm InP HEMT ultra low noise amplifier. In Proceedings of the 2014 Asia-Pacific Microwave Conference, Sendai, Japan, 4-7 November 2014; pp. 229-231.

16. Estella, N.; Bui, L.; Camargo, E.; Schellenberg, J. 35nm InP HEMT LNAs at E/W-Band Frequencies. In Proceedings of the 2016 IEEE Compound Semiconductor Integrated Circuit Symposium (CSICS), Austin, TX, USA, 23-26 October 2016; pp. 1-3.

17. Thome, F.; Leuther, A.; Heinz, F.; Ambacher, O. W-Band LNA MMICs Based on a Noise-Optimized 50-nm Gate-Length Metamorphic HEMT Technology. In Proceedings of the 2019 IEEE MTT-S International Microwave Symposium (IMS), Boston, MA, USA, 2-7 June 2019; pp. 168-171.

18. Velazco, J.E.; Ledezma, L.; Bowen, J.; Samoska, L.; Soriano, M.; Akgiray, A.; Weinreb, S.; Lazio, J. Ultra-Wideband Low Noise Amplifiers For The Next Generation Very Large Array. In Proceedings of the 2019 IEEE Aerospace Conference, Big Sky, MT, USA, 2-9 March 2019; pp. 1-6.

19. Nilsson, P.Å.; Pourkabirian, A.; Schleeh, J.; Wadefalk, N.; Starski, J.P.; Alestig, G.; Halonen, J.; Nilsson, B.; Zirath, H.; Grahn, J. Cryogenic low noise amplifiers in an InP HEMT MMIC process. In Proceedings of the 2015 Asia-Pacific Microwave Conference (APMC), Nanjing, China, 6-9 December 2015; Volume 1, pp. 1-3.

20. Schleeh, J.; Wadefalk, N.; Nilsson, P.; Starski, J.P.; Grahn, J. Cryogenic Broadband Ultra-Low-Noise MMIC LNAs for Radio Astronomy Applications. IEEE Trans. Microw. Theory Tech. 2013, 61, 871-877. [CrossRef]

21. Collantes, J.V.T.; de la Fuente, L.; Aja, B.; Artal, E. Cryogenic broadband Q-band MMIC low-noise amplifier. In Proceedings of the 2016 11th European Microwave Integrated Circuits Conference (EuMIC), London, UK, 3-4 October 2016; pp. 77-80.

22. Tang, Y.; Wadefalk, N.; Morgan, M.A.; Weinreb, S. Full Ka-band High Performance InP MMIC LNA Module. In Proceedings of the 2006 IEEE MTT-S International Microwave Symposium Digest, San Francisco, CA, USA, 11-16 June 2006; pp. 81-84.

23. Samoska, L.; Fung, A.; Kangaslahti, P.; Gawande, R.; Soria, M.; Lawrence, C.; Gaier, T.; Cuadrado-Calle, D.; George, D.; Fuller, G.; et al. Cryogenic low noise MMIC amplifiers for U-Band (40-60 GHz). In Proceedings of the 2016 11th European Microwave Integrated Circuits Conference (EuMIC), London, UK, 3-4 October 2016; pp. 81-84.

24. Pantoli, L.; Barigelli, A.; Leuzzi, G.; Vitulli, F. Analysis and design of a Q/V-band low-noise amplifier in GaAs-based $0.1 \mu \mathrm{m}$ pHEMT technology. IET Microw. Antennas Propag. 2016, 10, 1500-1506. [CrossRef]

25. Ciccognani, W.; Longhi, P.E.; Colangeli, S.; Limiti, E. Q/V band LNA for satellite on-board space applications using a 70 nanometers GaAs mHEMT commercial technology. Microw. Opt. Technol. Lett. 2018, 60, 2185-2190. [CrossRef]

26. Kotiranta, M.; Türk, S.; Schäfer, F.; Leuther, A.; Goliasch, J.; Massler, H.; Schlechtweg, M. Cryogenic 50-nm mHEMT MMIC LNA for 67-116 GHz with $34 \mathrm{~K}$ noise temperature. In Proceedings of the 2016 Global Symposium on Millimeter Waves (GSMM) ESA Workshop on Millimetre-Wave Technology and Applications, Espoo, Finland, 6-8 June 2016; pp. 1-3. 
27. Bryerton, E.W.; Mei, X.; Kim, Y.; Deal, W.; Yoshida, W.; Lange, M.; Uyeda, J.; Morgan, M.; Lai, R. A W-band low-noise amplifier with 22K noise temperature. In Proceedings of the 2009 IEEE MTT-S International Microwave Symposium Digest, Boston, MA, USA, 7-12 June 2009; pp. 681-684.

28. Kangaslahti, P.; Cleary, K.; Kooi, J.; Samoska, L.; Lai, R.; Barsky, M.; Mei, X.; Sarkozy, S.; Varonen, M. Sub-20-K noise temperature LNA for 67-90 GHz frequency band. In Proceedings of the 2017 IEEE MTT-S International Microwave Symposium (IMS), Honololu, HI, USA, 4-9 June 2017; pp. 1965-1968.

29. Tessmann, A.; Leuther, A.; Massler, H.; Wagner, S.; Thome, F.; Schlechtweg, M.; Ambacher, O. A millimeter-wave low-noise amplifier MMIC with integrated power detector and gain control functionality. In Proceedings of the 2016 IEEE MTT-S International Microwave Symposium (IMS), San Francisco, CA, USA, 22-27 May 2016; pp. 1-3.

30. Thome, F.; Leuther, A.; Gallego, J.D.; Schafer, F.; Schlechtweg, M.; Ambacher, O. 70-116-GHz LNAs in 35-nm and 50-nm Gate-Length Metamorphic HEMT Technologies for Cryogenic and Room-Temperature Operation. In Proceedings of the 2018 IEEE/MTT-S International Microwave Symposium(IMS), Philadelphia, PA, USA, 10-15 June 2018; pp. 1495-1498.

31. Smith, P.M.; Ashman, M.; Xu, D.; Yang, X.; Creamer, C.; Chao, P.C.; Chu, K.; Duh, K.H.; Koh, C.; Schellenberg, J A 50nm MHEMT millimeter-wave MMIC LNA with wideband noise and gain performance. In Proceedings of the 2014 IEEE MTT-S International Microwave Symposium (IMS2014), Tampa, FL, USA, 1-6 June 2014; pp. 1-4.

32. Ciccognani, W.; Colangeli, S.; Longhi, P.E.; Limiti, E. Design of a MMIC low-noise amplifier in industrial gallium arsenide technology for E-band 5G transceivers. Microw. Opt. Technol. Lett. 2019, 61, 205-210. [CrossRef]

33. Samoska, L.; Varonen, M.; Reeves, R.; Cleary, K.; Gawande, R.; Kangaslahti, P.; Gaier, T.; Lai, R.; Sarkozy, S. W-Band cryogenic InP MMIC LNAs with noise below $30 \mathrm{~K}$. In Proceedings of the 2012 IEEE/MTT-S International Microwave Symposium Digest, Montreal, QC, Canada, 17-22 June 2012; pp. 1-3.

34. Ciccognani, W.; Giannini, F.; Limiti, E.; Longhi, P.E. Full W-Band High-Gain LNA in mHEMT MMIC Technology. In Proceedings of the 2008 European Microwave Integrated Circuit Conference, Amsterdam, The Netherlands, 27-28 October 2008; pp. 314-317.

35. Varonen, M.; Reeves, R.; Kangaslahti, P.; Samoska, L.; Akgiray, A.; Cleary, K.; Gawande, R.; Fung, A.; Gaier, T.; Weinreb, S.; et al. A 75-116-GHz LNA with 23-K noise temperature at $108 \mathrm{GHz}$. In Proceedings of the 2013 IEEE MTT-S International Microwave Symposium Digest (MTT), Seattle, WA, USA, 2-7 June 2013; pp. 1-3.

36. Bessemoulin, A.; Tarazi, J.; McCulloch, M.G.; Mahon, S.J. 0.1- $\mathrm{mm}$ GaAs PHEMT W-band low noise amplifier MMIC using coplanar waveguide technology. In Proceedings of the 2014 1st Australian Microwave Symposium (AMS), Melbourne, Australia, 26-27 June 2014; pp. 1-2.

37. Cleriti, R.; Ciccognani, W.; Colangeli, S.; Serino, A.; Limiti, E.; Frijlink, P.; Renvoisé, M.; Doerner, R.; Hossain, M. D-band LNA using a 40-nm GaAs mHEMT technology. In Proceedings of the 2017 12th European Microwave Integrated Circuits Conference (EuMIC), Nuremberg, Germany, 8-10 October 2017; pp. 105-108.

38. Larkoski, P.V.; Kangaslahti, P.; Samoska, L.; Lai, R.; Sarkozy, S.; Church, S.E. Low noise amplifiers for $140 \mathrm{GHz}$ wide-band cryogenic receivers. In Proceedings of the 2013 IEEE MTT-S International Microwave Symposium Digest (MTT), Seattle, WA, USA, 2-7 June 2013; pp. 1-4.

39. Kangaslahti, P.; Pukala, D.; Gaier, T.; Deal, W.; Mei, X.; Lai, R. Low noise amplifier for $180 \mathrm{GHz}$ frequency band. In Proceedings of the 2008 IEEE MTT-S International Microwave Symposium Digest, Atlanta, GA, USA, 15-20 June 2008; pp. 451-454.

40. Moschetti, G.; Leuther, A.; Maßler, H.; Aja, B.; Rösch, M.; Schlechtweg, M.; Ambacher, O.; Kangas, V.; Geneviève-Perichaud, M. A 183 GHz Metamorphic HEMT Low-Noise Amplifier with 3.5 dB Noise Figure. IEEE Microw. Wirel. Compon. Lett. 2015, 25, 618-620. [CrossRef]

41. Tessmann, A.; Hurm, V.; Leuther, A.; Massler, H.; Weber, R.; Kuri, M.; Riessle, M.; Stulz, H.-P.; Zink, M.; Schlechtweg, M.; et al. $243 \mathrm{GHz}$ low-noise amplifier MMICs and modules based on metamorphic HEMT technology. Int. J. Microw. Wirel. Technol. 2014, 6, 215-223. [CrossRef]

42. Samoska, L.A. An Overview of Solid-State Integrated Circuit Amplifiers in the Submillimeter-Wave and THz Regime. IEEE Trans. Terahertz Sci. Technol. 2011, 1, 9-24. [CrossRef] 
43. Pace, L.; Ciccognani, W.; Colangeli, S.; Longhi, P.E.; Limiti, E.; Leblanc, R. A Ka-Band Low-Noise Amplifier for Space Applications in a $100 \mathrm{~nm}$ GaN on Si technology. In Proceedings of the PRIME 2019-15th Conference on Ph.D. Research in Microelectronics and Electronics, Lausanne, Switzerland, 15-18 July 2019; pp. 161-164.

44. Doo, J.; Park, W.; Choe, W.; Jeong, J. Design of Broadband W-Band Waveguide Package and Application to Low Noise Amplifier Module. Electronics 2019, 8, 523. [CrossRef]

(C) 2019 by the authors. Licensee MDPI, Basel, Switzerland. This article is an open access article distributed under the terms and conditions of the Creative Commons Attribution (CC BY) license (http://creativecommons.org/licenses/by/4.0/). 